\title{
The Influence of Stress Factors towards Psychological Well- Being among Part-Time Students at UiTM Shah Alam
}

Mohd Safwan Ramli, Nur Hidayah Ayob, Noor Dalila Musa, Arifi Ridzuan, Zaidatul Nadhirah Roslan

To Link this Article: http://dx.doi.org/10.6007/IJARBSS/v12-i1/12156

DOI:10.6007/IJARBSS/v12-i1/12156

Received: 13 November 2021, Revised: 17 December 2021, Accepted: 29 December 2021

Published Online: 15 January 2022

In-Text Citation: (Ramli et al., 2022)

To Cite this Article: Ramli, M. S., Ayob, N. H., Musa, N. D., Ridzuan, A., \& Roslan, Z. N. (2022). The Influence of Stress Factors towards Psychological Well-Being among Part-Time Students at UiTM Shah Alam. International Journal of Academic Research in Business and Social Sciences, 12(1), 1351-1364.

Copyright: (c) 2022 The Author(s)

Published by Human Resource Management Academic Research Society (www.hrmars.com)

This article is published under the Creative Commons Attribution (CC BY 4.0) license. Anyone may reproduce, distribute, translate and create derivative works of this article (for both commercial and non0-commercial purposes), subject to full attribution to the original publication and authors. The full terms of this license may be seen

at: http://creativecommons.org/licences/by/4.0/legalcode

Vol. 12, No. 1, 2022, Pg. 1351 - 1364

Full Terms \& Conditions of access and use can be found at http://hrmars.com/index.php/pages/detail/publication-ethics 


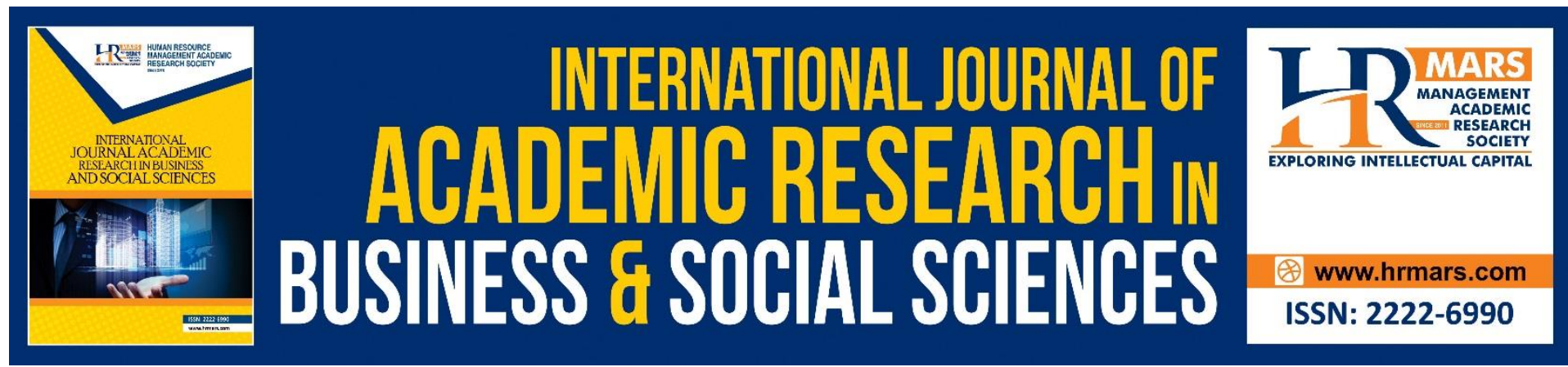

\title{
The Influence of Stress Factors towards Psychological Well-Being among Part-Time Students at UiTM Shah Alam
}

\author{
Mohd Safwan Ramli, Nur Hidayah Ayob, Noor Dalila Musa, \\ Arifi Ridzuan, Zaidatul Nadhirah Roslan \\ Faculty of Business and Management, Universiti Teknologi MARA (UiTM) Jengka, Pahang, \\ Malaysia \\ Correspondence Author: safwanramli@uitm.edu.my
}

\begin{abstract}
The World Health Organisation (WHO) describes stress as "the reaction people may have when presented with demands and pressures that are not matched to their knowledge and abilities and which challenge their ability to cope." However, if stress is extreme and goes on for some time, it can turn to mental and physical ill-health. Oftentimes, obstacles and problems in life may easily cause stress among part-time students at UiTM Shah Alam. The psychological well-being of part-time students is very important as it brings an influence the performance of their work and study life.

Thus, it is essential to study the influence of stress factors on psychological well-being among Part-Time Students at UiTM Shah Alam. The framework for the study is adopted from Kawano Yuri (2008) use as an independent variable to measure the main factor of stress, which is work stress, family stress, academic stress, financial stress, and self -efficacy while the dependent variable is the student psychological well-being towards the stress factors. A total of 216 respondents were selected using a stratified sampling technique which focused on a group of Part-Time Students who currently studied at UiTM Shah Alam. A complete set of questionnaires using a concept adapted and adopted from Rift (2004) was sent to respondents via WhatsApp and other social media platforms due to pandemic covid-19 constraints. All the data collected were analyzed using SPSS version 26 . Based on the findings discovered that all the five dimensions of stress factors, namely work stress, family stress, academic stress, financial stress, and self-efficacy were found to have positive relationships with psychological well-being $(r=.179, p, p<0.01 ; r=.443, p<0.01 ; r=.875, p<0.01 ; r=.172$, $p<0.01, r=.345, p<0.01$ respectively). These positive relationships indicated that the greater the work stress, family stress, academic stress, financial stress, and self-efficacy, the greater it will impact psychological well-being among part-time students. Furthermore, the finding of the study also revealed work stress become the most influential dimension of stress factor among part-time students in UiTM Shah Alam $(\beta=0.995, p<0.00)$. However, the other three dimensions of family stress, financial stress, and self-efficacy do not have an influence on psychological well-being among part-time students whereas academic stress was found to have a negative influence on the psychological well-being among part-time students $(\beta=-$
\end{abstract}


$0.214, p>0.02$ ). Therefore, it was discovered that only two out of five dimensions of stress factors acted as predictors towards psychological well-being among part-time students in UiTM Shah Alam. The study concluded that a better understanding of the issues of stress by the universities would provide some insights on how they can assist the part-time students in dealing with the stress, thus enabling the students to increase their performance in work and study.

Keywords: Psychological Well-Being, Work Stress, Family Stress, Academic Stress, Financial Stress, Self-Efficacy

\section{Introduction}

Additional education is often required to maintain employment and grow within an organization or job. Part-time students differed from full-time students in their early education, lifestyles, employment experiences, educational goals, and learning process.

Nowadays, many students work while they study due to financial constraints. According to The Star (2018), university student employment rates are high internationally at $83 \%$, while in Malaysia, nine out of ten students work while studying, most typically to increase their income. Malaysian university students are increasingly engaging in paid work alongside their studies to help bridge a substantial gap between the expense of education and parental finance (The Star, 2018). According to Rozana (2018), HSBC's The Value of Education - The Price of Success research, which surveyed over 10,000 parents and 1,500 students in 15 countries, including Malaysia, found that university students confront cash shortages despite getting financial aid from their parents. Apart from tuition fees, students must also cover other expenses such as accommodation, educational resources and assignment-related materials, transportation, as well as monthly utilities and other living expenses.

Not all students, however, work to assist in funding their school. Rozana (2018) reports that $53 \%$ of Malaysian students work part-time to increase their employability in a highly competitive employment market. A glimpse of real-world skills and experiential learning is critical for graduates seeking to create possibilities for themselves throughout their tertiary education. Working part-time while enrolled in school enables students to earn additional funds to offset the costs associated with their education. However, it serves as a means of future savings (Rozana, 2018). Additionally, Siti, Yusup \& Awang (2012) defined adult learners as individuals aged 25 to 50 who seek education in response to employment demands. Certain adult learners want advancement, and obtaining a higher degree of education is one method to do this. Apart from employment or professional advancement, adult learners may choose to continue their education at a higher level to meet society's needs. They need a higher wage than they currently earn. If they have a bachelor's degree, for instance, they may look for higher-paying work in other locations. Additionally, the increasing number of family number pushes them to study since they must provide for their families. Not to mention the increase in the cost of goods.

As a result of their high level of commitment, part-time students experience stress, which negatively affects their psychological well-being. According to Roslan et al (2017), parttime students often face obstacles and setbacks that prevent them from completing their education. Additionally, students must avoid excessive stress, which is becoming increasingly concerning, as the number of psychological issues and their severity have been discovered to be growing among the student population. Additionally, issues such as financial restrictions and time constraints, which limit the number of times students have to finish assignments 
and research papers owing to employment, school, and family obligations, affect students' psychological well-being. Students' psychological well-being and mental state may affect their positive learning and task performance (Roslan, et al., 2017).

Part-time students may experience stress as a result of their academic, financial, and interpersonal situations and support systems, with anxiety levels often peaking around assessment deadlines and examination times (He, Turnbull, Kirshbaum, Phillips \& KlaininYobas, 2018). According to Shamsuddin et al (2013), numerous studies have revealed that depression, anxiety, and stress symptoms affect students' performance in school, college, and university, impairing academic achievement, deteriorating relationships, causing marital problems, and affecting future employment. Apart from meeting academic and social expectations, university students must adjust to a variety of psychological changes as they prepare for their professional careers. The high bar for academic accomplishment has produced a very stressful atmosphere for students, which may be detrimental to both physical and mental health if left unchecked. Increased educational attainment results in increased academic stress, a decrease in academic assistance, social isolation during the adjustment phase, and the possibility of long-term financial debt. Constant pressure may result in a decline in the academic performance of university students. Additionally, they must be isolated from family and friends (Shahira et al., 2018).

\section{Problem Statement}

Stress is a common phrase that everyone uses casually when confronted with a difficult situation. Part-time students enrolled in post-secondary schools face the same issues. Obstacles and problems in life may easily result in stress. The same number of challenges and obstacles may have varying consequences on various individuals. Ganesan, Talwar, Norsiah \& Oon (2018) indicate that many students suffer various types of stress as a result of their surroundings and academic pressure. Stressors such as a heavy workload, unclear assignments, inability to understand the context, feelings of incompetence, low motivation to learn, participation in-class presentations, relationships with family and friends, time constraints, and sleeping habits can all affect some students' mental health (Ganesan, 2018).

Additionally, part-time students face several obstacles in their everyday lives. As a result, the concept of dynamic university life is revealed by these obstacles, which lead to stress (Pariat et al., 2014). Many of them experience problems and setbacks in their academic and professional lives. Stress has become a way of life for some university students. Students are often confronted with a variety of personal and interpersonal difficulties, and their inability to embrace the challenges and responsibilities of the university has become one of the most frequently cited reasons for students to withdraw from their tertiary education (Abdullah et al., 2010). As a consequence, education in the contemporary era has become a commodity. Due to the flexibility of the study plan and study intervals, students may choose their study schedule and study hours. A part-time study is a popular option for working parttime students since it does not force them to quit their careers or spend $100 \%$ of their time on their studies. Working part-time students may continue their education via online distance learning (ODL) and hybrid learning without obtaining study leave or abandoning their jobs. They may quickly acquire information anywhere, such as at their place of employment, in a café, or at home (Mirkholikovna, 2020).

Students who work and study often encounter a variety of challenges in their everyday lives. They are responsible for several tasks associated with their study. Several are main caregivers and providers for their families. Due to the range of activities and obligations that 
must be fulfilled, such as family, career, and school, studying part-time requires a level of commitment and sacrifice that may result in significant strain (Siti, et al., 2012). It resulted in stressors such as job stress, home stress, academic stress, financial stress, and self-efficacy, all of which contributed to part-time students' discontent and discouragement. University and college administrators must be aware of students' need to work part-time and include flexible class schedules into assignments and course requirements. This may be a realistic option for students seeking to help relieve (Wang, \& Chen, 2017).

Stress is a concerning issue that emerges around part-time students nowadays. According to Siti, et al (2012), a vital initial step is to identify the stressors or sources of stress. Thus, the approach used in this research to identify stress among part-time students at UiTM Shah Alam is rational and reasonable. The goal of this study is to ascertain the extent to which part-time students at UiTM Shah Alam suffer environmental stress. Part-time students from UiTM Shah Alam participate in this course through Online Distance Learning (ODL) or hybrid learning. This analysis uncovered five factors or stressors. Work stress, family stress, academic stress, financial stress, and self-efficacy are all examples of stress. According to Abdul Rahman (2018), if a student is unable to strike a balance between employment and school, they may suffer consequences such as inadequate flexible time, high stress, and an excessive workload. The primary focus of this study is psychological well-being. The hypothesis is that there is a positive link between psychological well-being and stress among part-time students.

\section{Literature Review}

This study highlights the concepts of stress factor as the independent variables and the interrelated factors of psychological wellbeing as the dependent variables.

\section{Psychological Well-Being}

According to Shahira et al (2018), psychological well-being is defined as an individual's ability to exert control over their lives and activities. Psychological well-being does not always contain positive feelings; it also includes negative emotions such as frustration, disappointment, and loss, all of which are natural parts of life. As a result, regulating unpleasant emotions is critical for long-term health. Additionally, comprehension of psychological well-being is hampered by the substitution of different concepts. For instance, terms like "happiness," "mood, "affect, "subjective well-being," "quality of life," "life satisfaction," and "emotional health" are often employed. The various interpretations of these concepts led to changes in the measurement of psychological disorders as well as difficulties in understanding mental health and well-being.

\section{Work Stress}

Work is a significant part of the lives of the majority of adults, both economically and socially and psychologically. According to Daly (2017), job-related stress may be created by work or increased by employment. Individuals might suffer real consequences as a result of work stress, including severe effects on their behavior and health. Stress in the workplace is often caused by conflict, bullying, a lack of communication, and stress from home that affects a person's performance, among other factors. Work stress does have a relationship with psychological well-being. The increase of work stress can negatively impact the psychological well-being of students. This can be proved by a study by Suleman, Hussain, Shehzad, Syed \& Raja (2018) stating that perceived work stress has a detrimental and negative influence on 
mental health, as evaluated by sleeplessness, sadness, psychological well-being, anxiety, and happiness.

\section{Family Stress}

Family stress is a part of life that is always due to happen, according to Murry, ButlerBarnes, Mayo-Gamble, \& Inniss-Thompson (2018), families make a serious effort to modify and adapt to the demands of stressful events and life changes. It is considered that family stress can influence part-time students to be stressed. There is a relationship between family stress and psychological well-being. The increase of family stress might hurt the psychological well-being of students. According to Murry et al (2018), family stress occurs in families when stressful life events occur and how families effectively or poorly handle such events will impact the psychological well-being of part-time students.

\section{Academic Stress}

According to Adom, Chukwuere \& Osei (2020), academic stress contains a variety of factors that create stress, referred to as stressors. These factors can be interpersonal, intrapersonal, social, health-related, or environmental and obstruct academic growth in educational institutions. Additionally, academic stress refers to psychological suffering caused by expected dissatisfaction linked with academic failure or simply by ignorance of the likelihood of such failure (Tiwari, 2016). Additionally, according to Ramli, Alavi, Mehrinezhad \& Ahmadi (2018), academic stress is the most prevalent emotional or mental condition that students encounter throughout their studies. Stress may be caused by a variety of factors, including a load of tests and exams, a challenging course, a foreign educational system, and contemplating plans after graduation. Academic stress has a relationship with psychological well-being. Increased academic stress can have a negative impact on students' psychological well-being. According to Ofori et al (2018), students who reported experiencing less academic stress had more positive interpersonal interactions and a greater sense of psychological wellbeing than students who reported experiencing more academic stress.

\section{Financial Stress}

Britt et al (2015) defined financial stress as an inability to pay one's financial commitments, which is impacted by one's attitudes, beliefs, and other psychological aspects. Financial stress is a well-documented factor in university student turnover, academic performance, retention, and overall health and well-being. Recent research indicates that students experiencing greater financial stress are more likely to seek professional financial counseling than students experiencing less financial stress, which may help mitigate some of the negative effects of financial stress on academic achievement and student well-being. Financial stress does have a relationship with psychological well-being. Financial problems may be significant burdens, particularly during prolonged economic downturns. According to Montpetit, Kapp \& Bergeman (2015), it is sometimes said that "money cannot buy happiness," it has been shown that stress, especially financial hardship, has a significant effect on psychological well-being.

\section{Self-Efficacy}

Self-efficacy, according to Maier, Haug \& Schaub (2015), is the capacity to begin and utilize effective stress coping skills, as well as to moderate the route from stress to illness. Additionally, the researchers discovered that students with high achievement objectives and 
self-efficacy outperformed their friends and colleagues. Besides that, according to Capron Puozzo \& Audrin (2021), self-efficacy refers to an individual's view and confidence in their abilities and their ability to motivate them effectively in order to succeed in a specific activity in the sense of accomplishing a goal. Self-efficacy has been found to have a significant impact on students' performance. Apart from that, Bandura eta I (1977) defined self-efficacy as the belief in one's ability to effectively execute the behaviors necessary to achieve the intended results. Self-efficacy, in its original definition, relates to a person's confidence in their capacity to do specified activities and behaviors within a particular situation. According to Siddiqui (2015), Albert Bandura's concept of self-efficacy refers to the judgments individuals make about their capacity to do given tasks or circumstances. Self-efficacy has a significant positive impact on psychological well-being among part-time students. As a result, part-time students with a high level of self-efficacy contribute to high levels of engagement and life satisfaction. Alternatively, if self-efficacy is low, psychological well-being is also low. If self-efficacy is high, psychological well-being is also high.

\section{Conceptual Framework}

Figure 1 depicts the framework for the study adapted from Kawano Yuri (2008) under the title "Association of job-related stress factors with psychological and somatic symptoms among Japanese hospital nurses" an empirical study in an emerging market, stress factor quality could increase the psychological well-being by striving to improve the part-time students psychological and other related factors in psychological well-being should be examined and suggests that the site design quality seems to be an important factor.

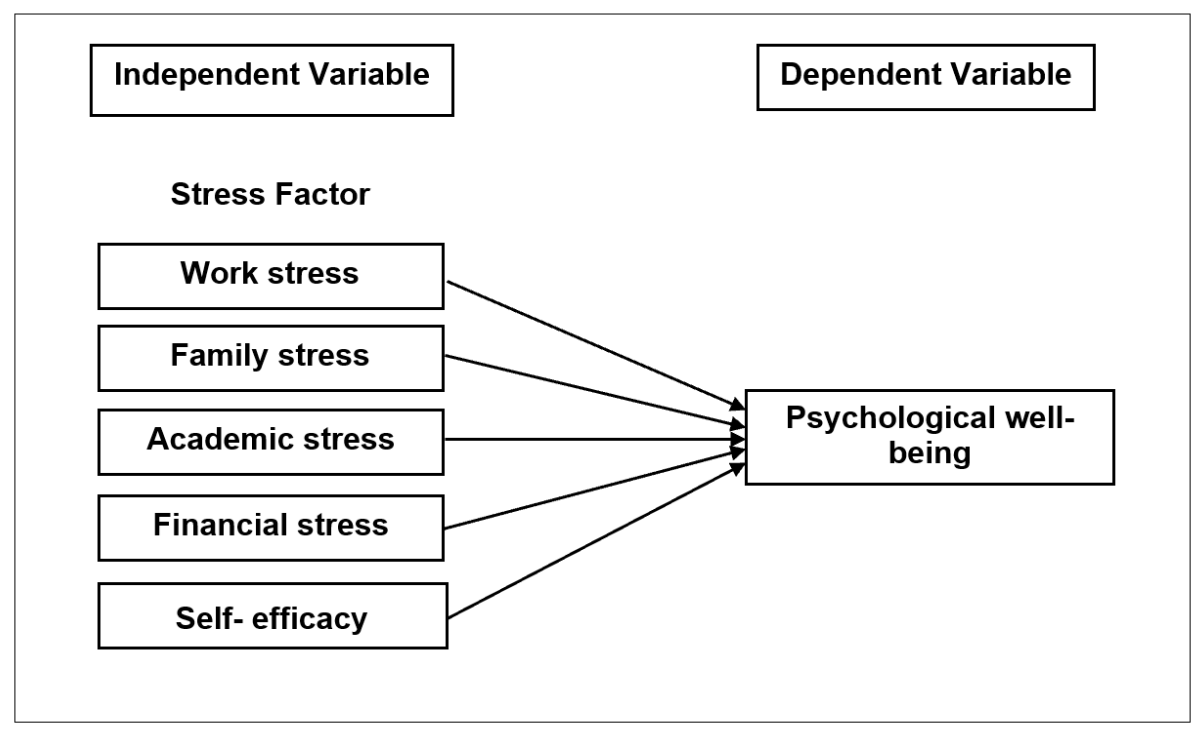

Figure 1: Conceptual Framework

\section{Research Questions}

Three research questions are formulated in the study namely:

1. What is the level of psychological well-being among part-time students?

2. What is the relationship between stress factors and psychological well-being among part-time students?

3. Which dimensions of stress factors predict psychological well-being among students? 


\section{Methodology}

The population of the study was UiTM Shah Alam part-time students' respondents and the sample size was determined using GPower calculation. Based on the effect size of 0.15 , an alpha level of 0.05 and five predictors, a total of 92 samples were suggested. However, according to Hair et al. (2014), the larger sample size improves precision and reliability. Furthermore, correlational research was adopted for this study. In addition, a Stratified Sampling Technique was applied. The questionnaire was sent to respondents via WhatsApp and social media platforms due to pandemic covid-19. The item for this study was adopted from a past study; Rift (2014). Some modifications were made to ensure the item met with the context of the study and the item was validated by the field of experts.

\section{Findings and Discussions}

In this study, the data was obtained from 216 respondents. A total of 174 respondents $(80.6 \%)$ are female, and 42 respondents (19.4\%) are male. Pertaining to the age distribution of the respondents, $85.2 \%$ is in the age group between 31 until 40 years old, 18 respondents (8.3\%) were aged between 31 until 40 years old and 14 respondents (6.5\%) are in the age of 21-30 years old. For income majority of respondents were from RM2000-RM3999 with the percentage of $(80.1 \%), 22$ respondents $(10.2 \%)$ were in the income of RM1000-RM1999 and lastly 14 respondents (6.5\%) (RM4000-RM6999).

Table 1: Demographic Details

\begin{tabular}{llrr}
\hline Demographic Details & \multicolumn{1}{c}{ Description } & Frequencies & Percentage \\
\hline Gender & Male & 42 & 19.4 \\
& Female & 174 & 80.6 \\
\hline Age & $21-30$ years old & 14 & 6.5 \\
& $31-40$ years old & 184 & 85.2 \\
& 41-50 years old & 18 & 8.3 \\
\hline Income & Below RM1000 & 7 & 3.2 \\
& RM1000-RM1999 & 22 & 10.2 \\
& RM2000-RM3999 & 173 & 80.1 \\
& RM4000-RM6999 & 14 & 6.5
\end{tabular}

\section{$R Q$ 1: What is the level of psychological well-being among part-time students?}

Descriptive statistics were computed for both independent and dependent variables in order to compare the level of psychological well-being among part-time students. The interpretation of the scores was based on the Best Principle (Thaoprom, 2004). Scores were divided by three ranges which are high, average and low with the computation like this: 5$1 / 3=1.33$.

Thus, the results are:

- Scores between 1.00-2.33 = Low Scores

- Scores between 2.34-3.67 = Moderate Scores

- Scores between 3.68-5.00 = High Scores

The assessment on the level of psychological well-being revealed that as indicated in Table 2. It was found that all dimensions were at a high level. 
Table 2: Level of Psychological Well-Being Among Part-Time Students

\begin{tabular}{|c|c|c|c|c|c|}
\hline Respondents & Variable & $\mathbf{N}$ & Mean & $\begin{array}{l}\text { Std } \\
\text { Deviation }\end{array}$ & Level \\
\hline & Work Stress & 21 & 3.986 & .72122 & High \\
\hline & & 6 & 1 & & \\
\hline & Family Stress & 21 & 3.744 & .85910 & High \\
\hline & & 6 & 2 & & \\
\hline \multirow[t]{2}{*}{ UiTM Shah Alam } & Academic Stress & 21 & 4.232 & .76172 & High \\
\hline & & 6 & 6 & & \\
\hline Part-Time & Financial Stress & 21 & 3.929 & .73488 & High \\
\hline \multirow[t]{8}{*}{ Students } & & 6 & 4 & & \\
\hline & Self-Effacing & 21 & 4.032 & .67306 & High \\
\hline & Stress & 6 & 4 & & \\
\hline & Overall Stress & 21 & 3.993 & .75140 & High \\
\hline & Factors & 6 & 5 & & \\
\hline & Overall & 21 & 4.472 & .61327 & High \\
\hline & Psychological & 6 & 9 & & \\
\hline & Well-Being & & & & \\
\hline
\end{tabular}

The findings based on the UiTM Part-Time student in Malaysia have been supported by various psychological well-being studies. Ganesan, Talwar, Norsiah \& Oon (2018) reported that the stress level and psychological well-being rapid growth that can cause emotional problems, depression, panic attacks, or other forms of anxiety and worry. The level of Academic Stress is higher it may cause the common stressors reported in an academic setting include excessive assignments, poor time management and social skills, peer competition and low support from family. As supported by Roslan, Ahmad, Nabilla, \& Ghiami (2017) the parttime students do may have emotional burned out due to the high-stress factor. Due to concerns, it is important to understand how academic stress in part-time students can affect other areas of life such as family life, parenting and work. Learning to effectively manage academic stress can significantly reduce anxiety and allow you to balance school, family and work.

\section{RQ 2: What is the relationship between stress factors and psychological well-being among part-time students?}

Table 3 illustrates the relationship between independent and dependent variables which will be interpreted by using Cohen (1988) guidelines positive relationship between the independent variable and dependent variables. Correlational analysis was conducted to determine the relationships between dimensions of stress factors and psychological wellbeing. The findings are tabulated in Table 2 which will be interpreted according to the guidelines by Cohen (1988). It was discovered that all five dimensions of stress factors had significant and positive relationships with psychological well-being. In fact, work stress, family stress, academic stress, financial stress and self-efficacy were found to have positive relationships with psychological well-being $(r=.179, p, p<0.01 ; r=.443, p<0.01 ; r=.875, p<0.01$; $r=.172, p<0.01, r=.345, p<0.01$ respectively). These positive relationships have signified that the greater the work stress, family stress, academic stress, financial stress and self-efficacy, the greater it will affect psychological well-being among part-time students. These findings 
are supported by Roslan, Ahmad, Nabilla, \& Ghiami, (2017) who found that stress factors may affect both psychological well-being among students, it can be concluded that stress can directly affect our abilities to create short-term memories, meaning it is more difficult to retain new information and keep it 'close at hand', inhibiting our natural learning processes.

Table 3: Correlation Between Stress Factors and Psychological Well-Being

\begin{tabular}{lcccccc}
\hline & 1 & 2 & 3 & 4 & 5 & 6 \\
\hline Work Stress & 1 & $.711^{* *}$ & $.249^{* *}$ & $.887^{* *}$ & $.624^{* *}$ & $.179^{* *}$ \\
\hline Family Stress & $.711^{* *}$ & 1 & $.611^{* *}$ & $.725^{* *}$ & $.721^{* *}$ & $.443^{* *}$ \\
\hline Academic Stress & $.249^{* *}$ & $.611^{* *}$ & 1 & $.263^{* *}$ & $.471^{* *}$ & $.875^{* *}$ \\
\hline Financial Stress & $.887^{* *}$ & $.725^{*}$ & $.263^{* *}$ & 1 & $.591^{* *}$ & $.172^{* *}$ \\
\hline Self-Efficacy & $.624^{* *}$ & $.721^{* *}$ & $.471^{* *}$ & $.591^{* *}$ & 1 & $.345^{* *}$ \\
\hline Psychological Well-Being & $.179^{* *}$ & $.443^{* *}$ & $.875^{* *}$ & $.172^{* *}$ & $.345^{* *}$ & 1 \\
\hline$* *$ Correlation is significant at the $\mathbf{0 . 0 1}$ level (1 tailed) & & & \\
\hline
\end{tabular}

RQ 3: Which dimensions of stress factors predict psychological well-being among students?

Table 4 shows the results of multiple regression analysis in determining the predictors of stress factors towards the psychological well-being among part-time students in UiTM Shah Alam, Malaysia. It was found that the R2 value was .785 in which all dimensions comprised of stress factors are explained $78.5 \%$ of the variance for psychological well-being. The findings have shown that work stress is the most influential dimension of stress factor towards psychological well-being among part-time students in Malaysia $(\beta=0.995, p<0.00)$, however another dimension such as family stress, financial stress and self-efficacy does not have influential on psychological well-being among part-time students. In the meantime, academic stress was found to have a negative influence on the psychological well-being of part-time students ( $\beta=-0.214, p>0.02$ ). Therefore, it can be concluded through these findings that only two out of five dimensions of stress factor acted as predictors towards the study's dependent variable which is psychological well-being. As stated by Siti, Yusup \& Rozaimie (2012) the interpretation of the value of stress factors among part time-student would affect their psychological well-being.

Table 4: Multiple Regression Analysis Between Dimensions of Stress Factors Towards Psychological Well-Being

\begin{tabular}{|c|c|c|c|c|}
\hline Respondents & $\begin{array}{l}\text { Independent } \\
\text { variables }\end{array}$ & Standardized Coefficients Beta & $\mathbf{t}$ & Sig. \\
\hline & Work Stress & .995 & 22.811 & .000 \\
\hline & Family Stress & .133 & 1.816 & .071 \\
\hline Part-Time & Academic Stress & -.214 & -3.156 & .002 \\
\hline \multirow[t]{6}{*}{ Students } & Financial Stress & -.937 & -.504 & .615 \\
\hline & Self-efficacy & -.035 & -.731 & .466 \\
\hline & R Square & & .785 & \\
\hline & $\mathrm{F}$ & & 152.939 & \\
\hline & Sig. F Value & & .000 & \\
\hline & Durbin Watson & & .717 & \\
\hline
\end{tabular}




\section{Conclusion and Recommendations}

This study focused on the influence of stress factors on psychological well-being among PartTime Students at UiTM Shah Alam. The results revealed that all dimensions of stress factors were at a high level which contributes to high levels of psychological well-being among parttime students. The results also confirmed that all the five dimensions had significant and positive relationships with psychological well-being. This signified that the greater the work stress, family stress, academic stress, financial stress, and self-efficacy, the greater it will affect psychological well-being among part-time students. The results also discovered that work stress was the most influential factor that contributes to psychological well-being whereas the dimensions of family stress, financial stress, and self-efficacy do not have an influence, meanwhile, academic stress has a negative influence on the psychological wellbeing of part-time students at UiTM Shah Alam. In conclusion, psychological well-being is a key aspect in achieving the goals and realizing the universities students' potential. The findings suggest that part-time students need extra attention from the university because without a healthy attitude towards academic goals, students can be overwhelmed with a lot of stress. The are several numbers of recommendations were identified with the aim to improve psychological well-being of part-time students as to make them feel happy both in their employment and student life. It is suggested to universities to promote wellbeing through the active recommendation of healthier habits related to physical wellbeing, such as better sleep, physical exercise and healthy eating, as well as activities that have been associated with better psychological and subjective wellbeing. Universities also can conduct regular workshops for students on stress management, assertive training, and communication skill as one of the intervention programs that can increase students' knowledge on how to handle stress, anxiety, and depression. Apart from it, the universities also are suggested to conduct a regular basis survey to evaluate the general wellbeing of the students. The result of the survey can be used by the universities authorities to understand the level of health needs of their students and to encourage them to design new programs or activities at the universities level in order to improve the self-efficacy and wellbeing of the students. Promoting the effectiveness of students' counseling centers also can become one of the recommendations to encourage students to get help from mental health professionals. Besides, mentoring program in the universities also enables students to share their stress or problems and to seek support and clarification from their mentor. All of this recommendation will assist students when they know that when they are in trouble or problems, they are not alone.

\section{Limitation and Recommendation for Future Research}

The major strength of the present study was a correlational study, as it could assess the direction of causality of the associations between Stress Factors and Psychological WellBeing among Part-Time Students at UiTM Shah Alam. However, the major limitation of this study was the sampling size focused only on the Part-Time Students who were currently studying at UiTM Shah Alam. Furthermore, data were obtained using a self-report questionnaire and thus, the researchers did not get comprehensive mental health history from each of the respondents. Nevertheless, the results may not be generalizable as the respondents involved were not equally distributed based on gender differences. Therefore, it is hoped that future research is proposed to be carried out using larger sample size and determining an equal number of genders' sizes. Moreover, future research also can be 
focused on the other dimensions of stress factors instead of work stress, family stress, academic stress, financial stress, and self-efficacy that contribute to psychological well-being.

\section{Theoretical and Contextual Contribution}

Since this study found stress factor element influences psychological well-being. Stress factor is an important element that was used to influence the psychological well-being. This used (Bandura, Adams, \& Beyer, (1977) model, which was the original concept of stress factor and rift model for psychological well-being. The results of the present study reduce a gap in the literature review of psychological well-being (Abdullah, Elias, \& Mahyuddin, 2010). The study by Britt, Canale, Fernatt, Stutz, \& Tibbetts, (2015) discover that stress factor influences the psychological well-being. In contract to previous research, this study employed stress factor to determine the psychological well-being effect in the context of part time student psychological well-being.

This study used social exchange theory to explain the relationship between stress factor and psychological well-being. It will be recalled in this study that stress factor element (work stress) was predicted and found to had relationship psychological well-being. The theory postulates that part time students' psychological behaviour from their university environment through observation, modelling and imitation. With the inclusion of stress factor in this study, social exchange theory has been validated and extended because it allowed part time students to imitate the stress factor laid down by other students.

\section{References}

Abdullah, M., Elias, H., Uli, J., \& Mahyuddin, R. (2010). Relationship between coping and university adjustment and academic achievement amongst first year undergraduates in a Malaysian Public University. International Journal of Arts and Sciences, 3(11), 379392.

Abdul Rahman, N. I. (2018). Stress, workload, time management and student performance.

Abranovic, W. A. (1997) Statistical Thinking and Data Analysis for Managers. Reading, MA: Addison-Wesley.

Bandura, A., Adams, N. E., \& Beyer, J. (1977). Cognitive processes mediating behavioral change. Journal of personality and social psychology, 35(3), 125.

Britt, S. L., Canale, A., Fernatt, F., Stutz, K., \& Tibbetts, R. (2015). Financial stress and financial counseling: Helping college students. Journal of Financial Counseling and Planning, 26(2), 172-186.

Puozzo, C. I., \& Audrin, C. (2021). Improving self-efficacy and creative self-efficacy to foster creativity and learning in schools. Thinking Skills and Creativity, 42, 100966. https://doi.org/10.1016/j.tsc.2021.100966

Daly, A. (2017). Stress, Employment and Academic Performance: A Study Exploring the Effects of Perceived Stress and Employment on a Third Level Student's Academic Performance (Doctoral dissertation, Dublin, National College of Ireland).

Ganesan, Y., Talwar, P., Norsiah, F., \& Oon, Y. B. (2018). A Study on Stress Level and Coping Strategies among Undergraduate Students. Journal of Cognitive Sciences and Human Development, 3(2), 37-47. https://doi.org/10.33736/jcshd.787.2018

He, F. X., Turnbull, B., Kirshbaum, M. N., Phillips, B., \& Klainin-Yobas, P. (2018). Assessing stress, protective factors and psychological well-being among undergraduate nursing students. Nurse education today, 68, 4-12. 
Maier, L. J., Haug, S., \& Schaub, M. P. (2015). The importance of stress, self-efficacy, and selfmedication for pharmacological neuroenhancement among employees and students. Drug and Alcohol Dependence, 156, 221-227.

Mirkholikovna, D. K. (2020). Advantages and disadvantages of distance learning. Наука и образование сегодня, (7 (54)).

Montpetit, Mignon A.; Kapp, Amy E.; Bergeman, C.S. (2015). Financial Stress, Neighborhood Stress, And Well-Being: Mediational and Moderational Models. Journal of Community Psychology, 43(3), 364-376. doi:10.1002/jcop.21684

Morin, A. (2020). How to improve your psychological well-being: Your emotional health is key to a happy life. Retrieved December 21, 2021 from https://www.verywellmind.com/improve-psychological-well-being-4177330

Murry, V. M., Butler-Barnes, S. T., Mayo-Gamble, T. L., \& Inniss-Thompson, M. N. (2018). Excavating new constructs for family stress theories in the context of everyday life experiences of Black American families. Journal of Family Theory \& Review, 10(2), 384405.

Murry, V. M., Butler-Barnes, S. T., Mayo-Gamble, T. L., \& Inniss-Thompson, M. N. (2018). Excavating new constructs for family stress theories in the context of everyday life experiences of Black American families. Journal of Family Theory \& Review, 10(2), 384405.

Ofori, I. N., Addai, P., Avor, J., \& Quaye, M. G. (2018). Too Much Academic Stress: Implications on Interpersonal Relationships and Psychological Well-being among Final Year University of Ghana Students. Asian Journal of Education and Social Studies, 2(3), 1-7. https://doi.org/10.9734/ajess/2018/43193

Pariat, L., Rynjah, A., Joplin., Kharjana, M. (2014). Stress Level of College Students: Interelationship between Stressors and Coping Strategies. IOSR Journal of Humanities and Social Sciences, 19(8), 40-46.

Ramli, N. H., Alavi, M., Mehrinezhad, S. A., \& Ahmadi, A. (2018). Academic stress and selfregulation among university students in Malaysia: Mediator role of mindfulness. Behavioral Sciences, 8(1), 12.

Roscoe, J. T. (1975) Fundamental Research Statistics for the Behavioural Sciences, 2nd edition. New York: Holt Rinehart \& Winston.

Roslan, S., Ahmad, N., Nabilla, N., \& Ghiami, Z. (2017). Psychological Well-being among Postgraduate Students. Acta Medica Bulgarica, 44(1), 35-41. https://doi.org/10.1515/amb-2017-0006

Rozana, S. (2018). When students work. NST Online. https://www.nst.com.my/education/2018/10/419737/when-students-work

Salkind, N. J. (2012). Exploring Research: Pearson Education, Inc, New Jersey.

Salkind, N. J. (2014). 100 questions (and answers) about statistics (Vol. 3). SAGE Publications.

Sekaran, U., \& Bougie, R. (2009). Research Methods for Business: A Skill Building Approach. Wiley, UK.

Sekaran, U., \& Bougie, R. (2010). Research Methods for Business: A Skill Building Approach. Wiley, UK.

Sekaran, U., \& Bougie, R. (2016). Research methods for business: A skill building approach. John Wiley \& Sons.

Shahira, M. N., Hanisshya, H., Lukman, Z. M., Normala, R., Azlini, C., \& Kamal, M. Y. (2018). Psychological Well-Being among University Students in Malaysia. International Journal of Research and Innovation in Social Science, 2, 133-137. 
Shahira, M. N., Hanisshya, H., Lukman, Z. M., Normala, R., Azlini, C., \& Kamal, M. Y. (2018). Psychological Well-Being among University Students in Malaysia. International Journal of Research and Innovation in Social Science, 2, 133-137.

Shamsuddin, K., Fadzil, F., Ismail, W. S. W., Shah, S. A., Omar, K., Muhammad, N. A., Jaffar, A., Ismail, A., \& Mahadevan, R. (2013). Correlates of depression, anxiety and stress among Malaysian university students. Asian Journal of Psychiatry, 6(4), 318-323. https://doi.org/10.1016/j.ajp.2013.01.014

Siti, H. S., Yusup, M. Y., \& Awang-Rozaimie, A. (2012). Environmental Stress among Part Time Students in Sarawak. Procedia - Social and Behavioral Sciences, 36, 96-102.

Siti, H. S., Yusup, M. Y., \& Awang-Rozaimie, A. (2012). Environmental Stress among Part Time Students in Sarawak. Procedia - Social and Behavioral Sciences, 36, 96-102.

Siddiqui, S. (2015). Impact of self-efficacy on psychological well-being among undergraduate students. The International Journal of Indian Psychology, 2(3), 5-16.

Smith, G. D., \& Yang, F. (2017). Stress, resilience and psychological well-being in Chinese undergraduate nursing students. Nurse education today, 49, 90-95.

Suleman, Q., Hussain, I., Shehzad, S., Syed, M. A., \& Raja, S. A. (2018). Relationship between perceived occupational stress and psychological well-being among secondary school heads in Khyber Pakhtunkhwa, Pakistan. PLOS ONE, 13(12), e0208143. https://doi.org/10.1371/journal.pone.0208143

Tiwari, G. (2016). A Comparative Study of Academic Stress Amongst Adolescents in Government and Public School. Jyotirmay Research Journal of Education, 3(1).

Wang, Y. C., \& Chen, C. J. (2017). College Students Part-Time Jobs: Factors and Challenges for Future Careers. 2017 6th IIAI International Congress on Advanced Applied Informatics (IIAI-AAI). Published. https://doi.org/10.1109/iiai-aai.2017.18 